Pacific Northwest

National Laboratory

Operated by Battelle for the U.S. Department of Energy

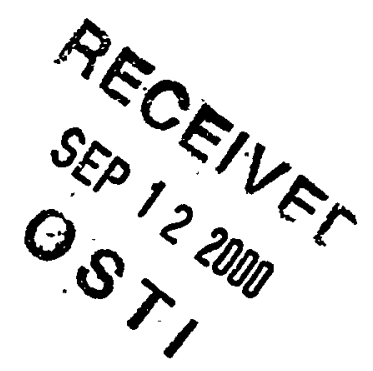

\section{The Chornobyl Accident, Radiation, and Health Concerns}

G. J. Vargo

August 2000

International Nuclear Safety Program

Pacific Northwest National Laboratory

Prepared for the U.S. Department of Energy under Contract DE-AC06-76RL01830 


\title{
DISCLAIMER
}

This report was prepared as an account of work sponsored by an agency of the United States Government. Neither the United States Government nor any agency thereof, nor Battelle Memorial Institute, nor any of their employees, makes any warranty, express or implied, or assumes any legal liability or responsibility for the accuracy, completeness, or usefulness of any information, apparatus, product, or process disclosed, or represents that its use would not infringe privately owned rights. Reference herein to any specific commercial product, process, or service by trade name, trademark, manufacturer, or otherwise does not necessarily constitute or imply its endorsement, recommendation, or favoring by the United States Government or any agency thereof, or Battelle Memorial Institute. The views and opinions of authors expressed herein do not necessarily state or reflect those of the United States Government or any agency thereof.

\author{
PACIFIC NORTHWEST NATIONAL LABORATORY \\ operated by \\ BATTELLE \\ for the \\ UNITED STATES DEPARTMENT OF ENERGY \\ under Contract DE-AC06-76RL01830
}

Printed in the United States of America
Available to DOE and DOE contractors from the Office of Scientific and Technical Information,
P.O. Box 62, Oak Ridge, TN 37831-0062;
ph: (865) 576-8401
fax: (865) 576-5728
email: reports@adonis.osti.gov

\author{
Available to the public from the National Technical Information Service, \\ U.S. Department of Commerce, 5285 Port Royal Rd., Springfield, VA 22161 \\ ph: (800) 553-6847 \\ fax: (703) 605-6900 \\ email: orders@ntis.fedworld.gov \\ online ordering: http://www.ntis.gov/ordering.htm
}

This document was printed on recycled paper. 


\section{DISCLAIMER}

\section{Portions of this document may be illegible in electronic image products. Images are produced from the best available original document.}




\section{The Chornobyl Accident, Radiation, and Health Concerns}

G. J. Vargo

August 2000

Prepared for the U.S. Department of Energy under Contract DE-AC06-76RL01830

International Nuclear Safety Program Pacific Northwest National Laboratory

Richland, Washington 99352 


\section{Contents}

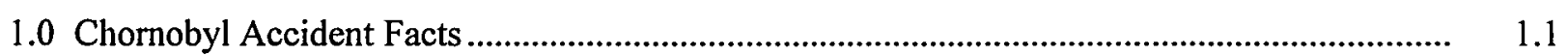

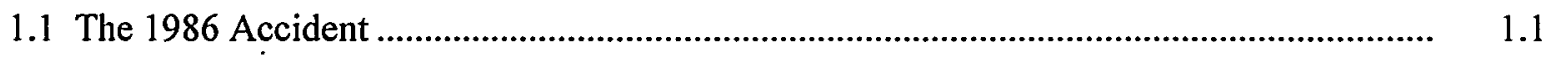

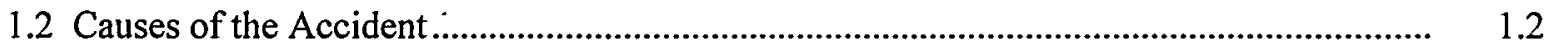

1.3 The Chornobyl Nuclear Power Plant Today ................................................................ 1.2

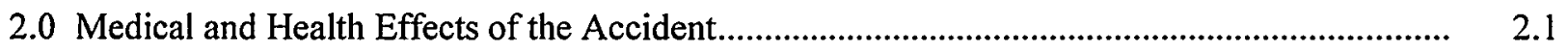

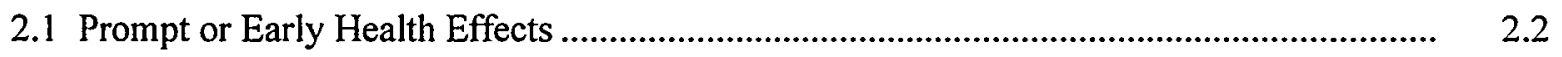

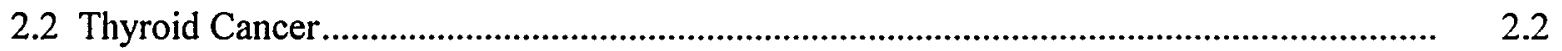

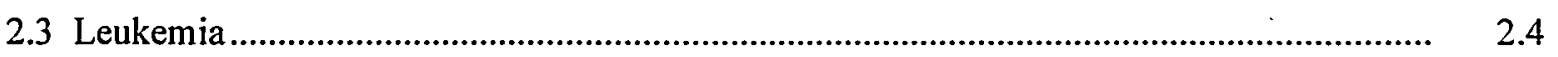

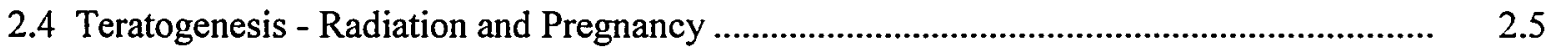

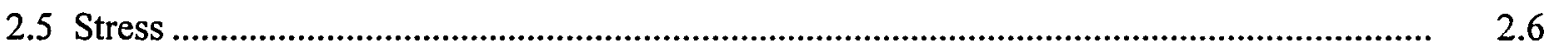

2.6 Conclusions Regarding the Medical and Health Effects of the Accident .......................... 2.6

3.0 Current Conditions at the Chornobyl Nuclear Power Plant Site .........................................

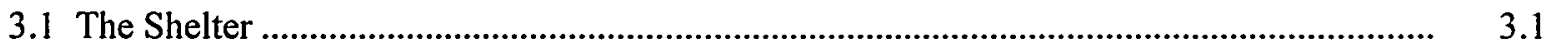

3.2 Restoration of the Chornobyl Nuclear Power Plant Site ..............................................

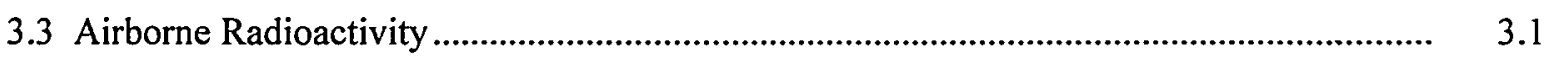

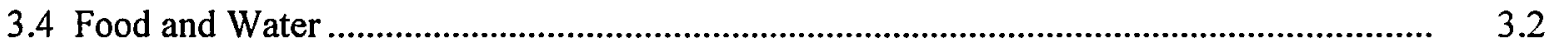

4.0 Current Conditions in the Chornobyl Exclusion Zone ................................................

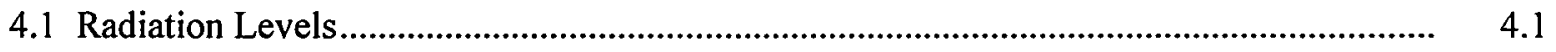

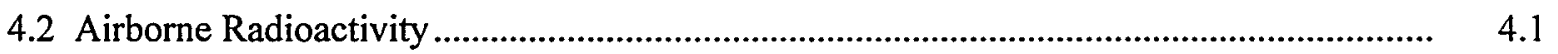

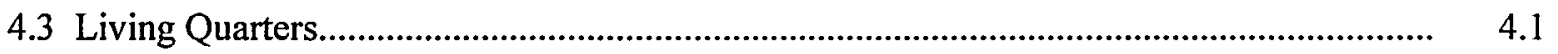

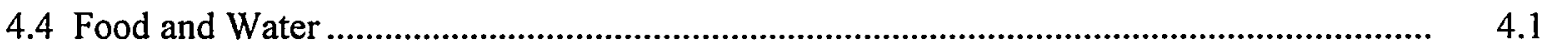




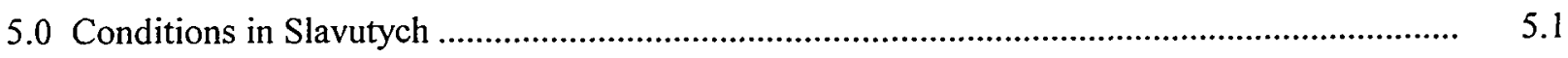

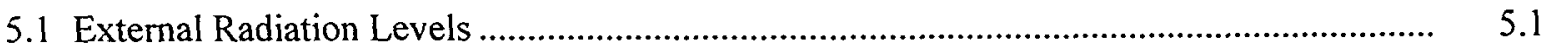

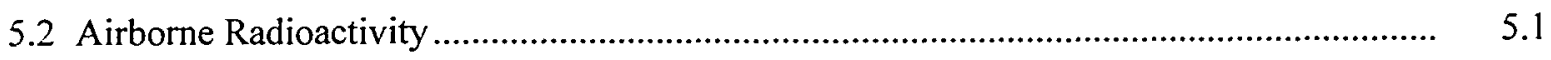

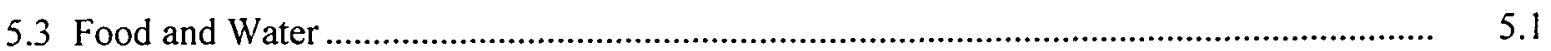

5.4 Total Dose to the Resident Population .................................................................... 5.1

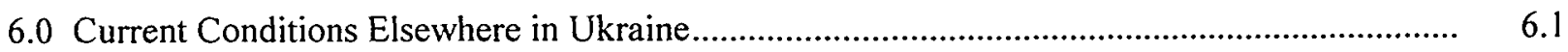

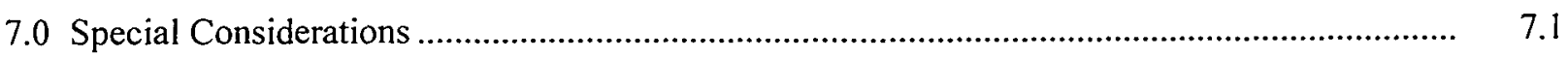

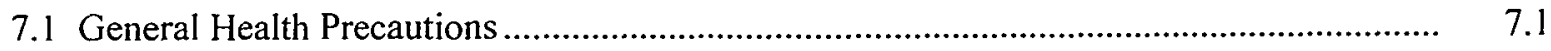

7.2 Special Accommodations for Physical Disabilities.................................................... 7.1

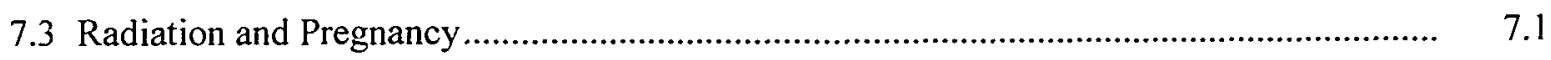

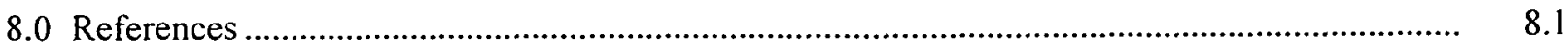




\section{Figures}

1.1 The Chornobyl Nuclear Power Plant As It Appears Today

1.3

\section{Tables}

2.1 Preliminary Estimates of Thyroid Doses Among Children in Ukraine and Belarus

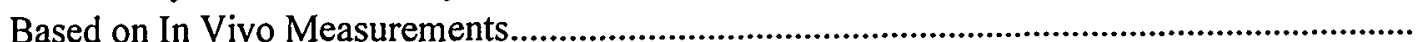

2.2 Number and Incidence of Child Thyroid Cancer in Belarus, Ukraine, and Russia Before and After the Chornobyl Accident. 


\subsection{Chornobyl Accident Facts}

\subsection{The 1986 Accident}

At 1:23 a.m. on April 26, 1986, an accident at Chornobyl Unit 4, a $1000 \mathrm{MWe} \mathrm{RBMK}^{(\mathrm{a})}$ nuclear power plant located in Ukraine, Soviet Union, resulted in destruction of the reactor core and part of the building in which the reactor was housed. In the initial steam explosion and subsequent fires, large amounts of radioactive material were released in the form of gases and dust particles. The energy released in the explosion was equivalent to 40 tons of TNT and resulted in discharge of about $4 \%$ of the reactor's nuclear fuel to the environment.

As a result of the initial explosion and subsequent fires, which continued for about 10 days after the accident, it is estimated that approximately 350 megacuries $(\mathrm{MCi} ;)^{(b)}$ of radioactive material were released to the environment (NEA 1996). Most of this radioactivity was in the form of short-lived ${ }^{(\mathrm{c})}$ noble gases such as krypton and xenon, which were quickly dispersed. Radioactive iodine, mainly ${ }^{131} \mathrm{I}$, was deposited on vegetation such as grass or was inhaled by emergency workers or members of the public near the site. The radioactive iodine also was concentrated in the milk of cows that grazed on the contaminated vegetation. In humans, iodine is concentrated in the thyroid gland. This iodine-cow-milk-human pathway was responsible for large doses to many children and accounts for one of the subsequent major health effects, as described below.

Some of the radioactive particles released from the accident were lifted as high as $10 \mathrm{~km} \mathrm{(6} \mathrm{miles)} \mathrm{by}$ the hot gases of the fire. Upper level winds carried these particles throughout portions of Ukraine, Belarus, and Russia, and smaller amounts were transported to portions of northern and western Europe. Fallout from this accident was detected in the United States, although the levels detected were very low.

(a) RBMK is a Russian acronym that literally means "high power pressure tube reactor." The RBMK reactor design was unique to the Soviet nuclear program. Instead of a large pressure vessel, the reactor consists of individual tubes, or channels that contain the nuclear fuel and cooling water. These tubes are surrounded by graphite, which moderates or slows down neutrons, allowing the nuclear chain reaction to be controlled. This reactor design also lacks the pressure containment system found in all western-designed nuclear power plants.

(b) The curie is a unit of radioactivity. Originally, the curie was defined in terms of the number of nuclear transformations occurring to one gram of radium-226 $\left({ }^{226} \mathrm{Ra}\right)$. One curie is equal to 37 billion nuclear $\left(3.7 \times 10^{10}\right)$ transformations per second. One megacurie is equal to one million curies.

(c) Different radioactive isotopes decay at different rates. The half-life of a radionuclide (or radioisotope) is the amount of time required for a quantity of radioactive material to decay (or transform) to one-half of its original value. Nearly all of the noble gases produced from nuclear fission have halflives that are on the order of minutes to hours. ${ }^{131} \mathrm{I}$, the most significant radioisotope of iodine, has a half-life of eight days. 
The principal environmental contaminants transported from the site were radioactive isotopes of iodine (mainly ${ }^{131} \mathrm{I}$ ) and cesium (primarily ${ }^{137} \mathrm{Cs}$ ). Smaller amounts of strontium (primarily ${ }^{90} \mathrm{Sr}$ ) were also released and detected.

\subsection{Causes of the Accident}

The root causes of the Chornobyl accident were 1) deficiencies in the plant design and 2) excessive reliance on administrative controls to fulfill critical safety functions. The design deficiencies combined with inadequate safety evaluation and multiple operator errors during a test of the turbine-generator system placed the reactor in an unstable operating condition.

\subsection{The Chornobyl Nuclear Power Plant Today}

In the first six months following the accident, a building called the "Shelter" was constructed around the remains of the destroyed reactor. Large quantities of topsoil, contaminated trees, and other vegetation on the plant site were removed and replaced. The other three remaining units at Chornobyl underwent extensive decontamination and rehabilitation so they could resume power production. Construction on two additional plants, Units 5 and 6 , ceased after the accident, and there are no plans to complete these plants.

The extensive contamination of the environment around the Chornobyl nuclear plant site led authorities to establish an "Exclusion Zone" approximately $30 \mathrm{~km}$ in diameter around the site. Access to this Exclusion Zone is controlled, and guards are posted at the entry points. Inhabitants of areas within the Exclusion Zone, including those from several hundred small villages, were relocated after the accident. In later years, elderly residents have been allowed to re-occupy their homes.

Because of the high radiation levels in the months immediately following the accident, the Shelter was constructed on top of the damaged remains of the original reactor building and non-compacted fill placed to assist with the control of contamination and the construction effort. In the years since it was constructed in 1986, some portions of the original structure have shifted and settled, and there are concerns about its long-term structural stability. Because of the settling, gaps have developed between some of the exterior panels of the Shelter. These gaps allow rain and snow to enter the structure, and this water must be treated and controlled to prevent additional environmental and nuclear safety problems.

Efforts to improve the structural stability of the Shelter and the ventilation stack that it shares with Unit 3 started in 1998 and are ongoing. Projects to seal the gaps in the Shelter exterior are planned.

After the initial extensive rehabilitation effort, the remaining three plants at Chornobyl were restarted. However, in 1991, Unit 2 was shut down after a fire that seriously damaged the plant's turbine generator. The fire had no effect on the nuclear portion of the plant. Unit 1 was shut down in 1996 as part of an international agreement to close and decommission the Chornobyl nuclear plant.

Approximately 6000 people work at the Chornobyl nuclear plant. Nearly all of them live in the City of Slavutych and commute to the site by bus or train each day. 
Today the only remaining operational unit at Chornobyl is Unit 3. Under the international agreement to close and decommission the Chornobyl nuclear plant, Unit 3 will cease operations by the end of the year 2000 .

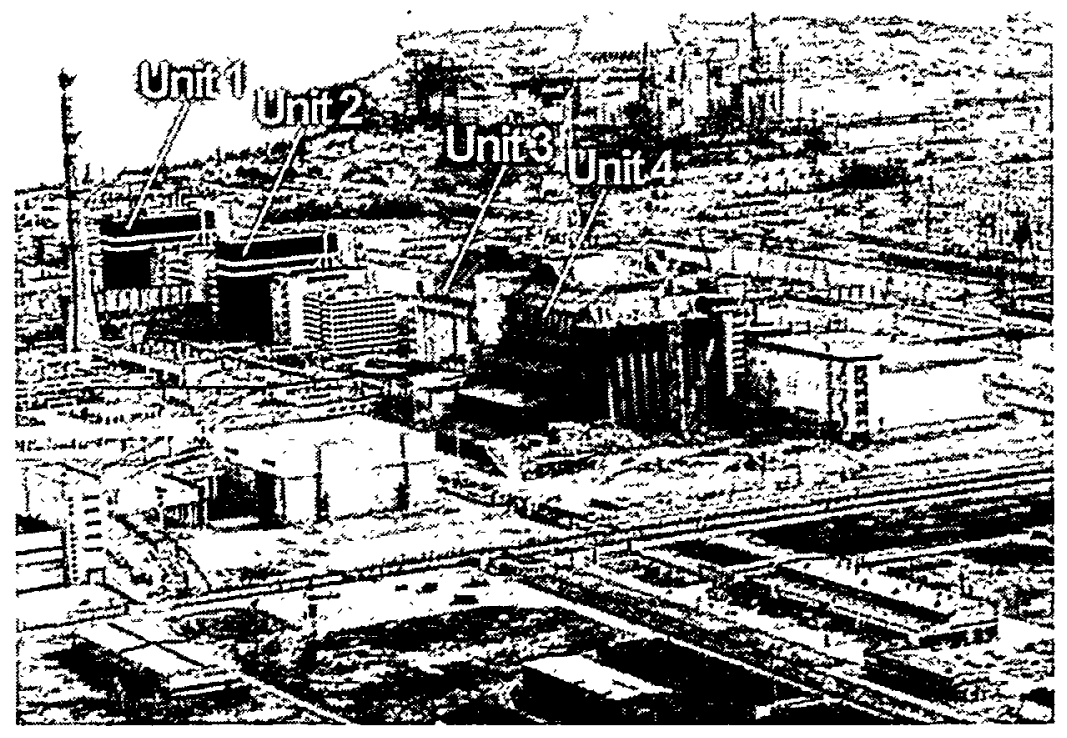

Figure 1.1. The Chornobyl Nuclear Power Plant As It Appears Today 


\subsection{Medical and Health Effects of the Accident}

The medical consequences of the Chornobyl accident often have been the subject of extreme claims that have no factual basis. A comprehensive treatment of the risks posed by the Chornobyl accident and its aftermath would be incomplete without some examination of these consequences and their implication for human health risk assessment. Some accounts place the number of accident-related fatalities at levels equivalent to nearly all of the deaths from all causes in the affected regions of Ukraine, Belarus, and Russia since 1986. There are many excellent publications dealing exclusively with the human health dimensions of the Chornobyl accident included in the references listed at the end of this report. This summary reviews five major health effects of the accident:

- acute radiation syndrome (ARS)

- thyroid cancer

- leukemia

- teratogenesis-effects on the embryo/fetus

- stress.

There are relatively few sources of data that can be used to evaluate the human health risks posed by ionizing radiation. Before the Chornobyl accident, the survivors of the atomic bombings of Hiroshima and Nagasaki were the largest human population that had been exposed to high radiation levels. Much of the current philosophy of radiation protection and human health risk estimation is based on this population along with much smaller groups of individuals who received significant exposures (e.g., the painters of radium watch dials). For the most part, the individuals in these populations received relatively high doses at high dose rates. Our understanding of these acute effects is based on a relatively small population. In addition, radiation accidents rarely involve uniform irradiation of an individual's whole body.

This summary of ARS is based on the 1988 Report of the United Nations Scientific Committee on the Effects of Atomic Radiation (UNSCEAR 1988) and summaries prepared by the International Atomic Energy Agency (IAEA 1988). The information about thyroid cancer is based primarily on data reported by Stsjazhko et al. (1995) and Likhtarev et al. (1994). The summary on leukemia is based on the 1986 statement of the IAEA as supported by subsequent publications including Ivanov et al. (1997) and Gluzman et al. (1999). The discussion of teratogenesis is based on a review published by Castronovo (1999). 


\subsection{Prompt or Early Health Effects}

Prompt or early health effects, often called acute effects, are those that occur within hours to weeks following a high absorbed dose, typically greater than 1 gray $(\mathrm{Gy})^{(\mathrm{a})}$ to the whole body. These effects exhibit a threshold below which they are not observed; however, above the threshold, the severity of the effects increases with increasing dose. These effects are sometimes called deterministic effects, although some deterministic effects such as cataracts can result from large doses accumulated over a much longer time. Acute effects may be life threatening depending on the magnitude of the dose and other factors such as the general health of the exposed individual and the effects of other injuries (e.g., burns). Victims of acute radiation exposure are often susceptible to infection that may prove fatal because of associated severely depressed immune response.

In the Chornobyl accident, acute effects were limited to those personnel who were on-site at the time of the accident or who were called to fight the fires that followed the explosion of the Unit- 4 reactor. Two people were killed immediately. The body of one of these people was never recovered, and the other person died of thermal burns the day following the accident. When combined with the 28 fatalities that occurred in the months following the accident, there were a total of 30 early fatalities attributed either in whole or in part to ARS.

Approximately 200 individuals were hospitalized either in regional hospitals or in specialized centers in Moscow and Kyiv. No members of the general public received doses sufficient to result in ARS.

\subsection{Thyroid Cancer}

The primary medical consequence of the Chornobyl accident was a dramatic increase in child thyroid cancer resulting from the consumption of milk contaminated with ${ }^{131} \mathrm{I}$ during the months immediately following the accident.

Stsjazhko et al. (1995) report dose estimates for approximately 100,000 children in Ukraine and Belarus based on in vivo measurements. These results are shown in Table 1. Of the children measured, $57 \%$ had doses less than $300 \mathrm{mGy}$. Approximately $7 \%$ had doses greater than $2 \mathrm{~Gy}$ and $0.6 \%$ (641 children) had doses greater than $10 \mathrm{~Gy}$. Studies to provide a more comprehensive assessment of the child thyroid doses are ongoing (Likhtarev et al. 1994). Most of the dose reconstruction is based on environmental measurements of ${ }^{137} \mathrm{Cs}$. The difference in the time course of the release, chemical behavior, and deposition between cesium and iodine introduces significant uncertainty into such estimates.

(a) The gray, abbreviated Gy, is the unit of absorbed dose in the International System (SI) of units. One gray is equal to an absorbed dose of one joule per kilogram $(\mathrm{J} / \mathrm{kg})$. One gray is also equal to 100 rads. 
Table 2.1. Preliminary Estimates of Thyroid Doses Among Children in Ukraine and Belarus Based on In Vivo Measurements

\begin{tabular}{||l|c|c|c|c|}
\hline $\begin{array}{l}\text { Estimated } \\
\text { thyroid dose } \\
\text { (mGy) }\end{array}$ & \multicolumn{2}{|l|}{ Belarus } & Ukraine \\
\cline { 2 - 5 } & Number & Percentage & Number & Percentage \\
\hline $0-300$ & 13,556 & 49.8 & 45,938 & 60.3 \\
\hline $300-1,000$ & 8,631 & 31.7 & 19,293 & 25.3 \\
\hline $1,000-2,000$ & 2,808 & 10.3 & 5,684 & 7.5 \\
\hline $2,000-5,000$ & 1,743 & 6.4 & 3,698 & 4.9 \\
\hline $5,000-10,000$ & 370 & 1.4 & 1,012 & 1.3 \\
\hline$>10,000$ & 111 & 0.4 & 530 & 0.7 \\
\hline Total & 27,217 & 100 & 76,155 & 100 \\
\hline Reference: Stsjazhko et al. (1995) \\
\hline
\end{tabular}

Table 2 shows the change in reported cancer cases before and following the Chornobyl accident. The post-accident incidence per million rose by as much as a factor of 200 from pre-1986 levels with an apparent latent period as short as 4 to 5 years. Tronko et al. (1999) report 577 cases of thyroid cancer in Ukraine between 1986 and 1997. Buglova et al. (1996) report that the incidence in boys is $50 \%$ higher than in girls. Goldman (1997) predicts that the ultimate number of cases will reach between 3000 and 6000 . The normal incidence of child thyroid cancer is low, typically less than 0.5 cases per million.

Table 2.2. Number and Incidence of Child Thyroid Cancer (children under 15 at time of diagnosis) in Belarus, Ukraine, and Russia Before and After the Chornobyl Accident.

\begin{tabular}{|l|c|c|c|c|c|c|}
\hline \multicolumn{1}{|c|}{ Area } & \multicolumn{3}{c|}{ Number } & \multicolumn{3}{c|}{ Rate (per million) } \\
\hline & $\mathbf{1 9 8 1 - 1 9 8 5}$ & $\mathbf{1 9 8 6 - 1 9 9 0}$ & $\mathbf{1 9 9 1 - 1 9 9 4}$ & $\mathbf{1 9 8 1 - 1 9 8 5}$ & $\mathbf{1 9 8 6 - 1 9 9 0}$ & $\mathbf{1 9 9 1 - 1 9 9 4}$ \\
\hline Belarus & 3 & 47 & 286 & 0.3 & 4.0 & 30.6 \\
\hline Gomel Region & 1 & 21 & 143 & 0.5 & 10.5 & 96.4 \\
\hline Ukraine & 25 & 60 & 149 & 0.5 & 1.1 & 3.4 \\
\hline Northern 5 Regions & 1 & 21 & 97 & 0.1 & 2.0 & 11.5 \\
\hline Russia & NA & NA & NA & NA & NA & NA \\
\hline $\begin{array}{l}\text { Bruansk, Kaluga } \\
\text { Regions }\end{array}$ & 0 & 3 & 20 & 0 & 1.2 & 10.0 \\
\hline $\begin{array}{l}\text { NA - Data not available. } \\
\text { Reference: Stsjazhko et al. (1995) }\end{array}$ & & & & & \\
\hline
\end{tabular}




\subsection{Leukemia}

An increase in the incidence of leukemia is a major concern following significant radiation exposure. According to analyses presented at the 1996 IAEA Vienna Conference on the Consequences of the Chornobyl Accident (IAEA 1996a), the total expected excess fatalities because of leukemia are estimated to be 470 among the 7.1 million inhabitants of contaminated areas and control zones. When compared to the expected normal spontaneous incidence of 25,000 cases among the 7.1 million people, these excess cases would be impossible to distinguish.

The expected number of cases among an assumed 200,000 Liquidators ${ }^{(a)}$ would be on the order of 200 cases compared to a spontaneous incidence of 800 cases. Using current models, 150 of the 200 expected excess leukemia cases would have been expected in the first 10 years after the accident, following a latent period of 3 to 5 years. The spontaneous incidence in the Liquidator population for the same period would be approximately 40 cases. To date, no consistent attributable increase in the rate of leukemia has been detected.

Ivanov et al. (1997) report no statistically significant difference in cancer morbidity or mortality between inhabitants of contaminated and uncontaminated areas of the Kaluga Oblast-(region) in Russia. Gluzman et al. (1999) report that while childhood leukemia represents one of the most likely health effects in a significantly exposed population, no significant increase has been observed.

It is also important to note that cancer rates in all areas of the former Soviet Union have increased since 1986, regardless of whether the areas experienced any significant contamination from the Chornobyl accident. Three factors confound development of meaningful conclusions on the link between the Chornobyl accident and an increase in the incidence of leukemia:

- the poor quality of data on incidence rates in affected areas of Ukraine, Belarus, and Russia before 1986

- selection bias for participation in health effect studies

- the general decline in nutrition and environmental quality throughout the countries of the former Soviet Union.

(a) The term applied to the workers who participated in early remediation activities at Chornobyl in 1986-1987. 


\subsection{Teratogenesis - Radiation and Pregnancy}

Ionizing radiation is a well-established teratogen ${ }^{(a)}$. Teratogenic effects are deterministic with a threshold of approximately 0.1 Gy (10 rads; ICRP 1993). The two specific effects of concern are severe mental retardation and cancer that may be expressed in childhood or adult life.

The potential for organ malformation in an embryo or fetus is highest when exposure to radiation occurs between the third and eighth weeks after conception. The natural incidence of such malformation is 0.06 , or approximately 1 in 17 live births.

Exposure to radiation during the eighth through the twenty-fifth week after conception carries the potential for severe mental retardation. Exposure during the period from the eighth through the fifteenth week results in the most significant effect with an observed shift of 30 intelligence quotient (IQ) points per Gy. Doses in the sixteenth week through the twenty-fifth week could show a similar, but less severe, effect per unit dose above the threshold.

The important point is that, while radiation exposure during pregnancy carries some risk, severe health effects to the embryo/fetus are associated with relatively large doses that are far in excess of environmental or occupational radiation exposure limits.

The risk of childhood cancers following irradiation in utero is believed to be approximately the same as for infants and children irradiated in the first decade of life (ICRP 1993), with a two to three times higher risk than the general population.

Castronovo (1999) provides a thorough review of embryo/fetal studies conducted throughout Europe and Asia Minor. Many studies that indicate an increase in fetal abnormality are flawed by poor data quality, bad experimental design, and selection bias. When such studies are discounted, there is no evidence that the radiation exposures of pregnant women arising from the Chornobyl accident produced any harmful effects.

There are, of course, many anecdotal accounts of birth defects and childhood cancers in Ukraine, Belarus, Russia, and in other countries contaminated by the Chornobyl accident (Kotz 1995). While the reality of these cases cannot be discounted, the spatial and temporal association of a particular disease or congenital abnormality does not equal causation. As noted previously here and elsewhere, the effects of decreased nutrition, stress, environmental pollution from a variety of non-radiological sources, and a general lack of preventive (and prenatal) medical care must be taken into consideration when attempting to analyze the cause of such cases. The data are inconclusive and indicate that ionizing radiation should not be considered in isolation from other human health risk factors in such a complex and dynamic system.

(a) A teratogen is an agent that interferes with the normal development of the embryo/fetus. A teratogen may produce physical defects in the offspring. 


\subsection{Stress}

It is likely that the greatest health effect of the Chornobyl accident is stress among those who were actually or potentially exposed to radiation or radioactive contamination. This is especially true among those who were forced to relocate because their homes or farms received radioactive contamination in excess of permissible levels.

Stress can manifest itself in a variety of forms. One of these is the dramatic increase in abortions performed in many parts of Europe and the Former Soviet Union in 1986 and 1987. Additional manifestations of stress can include increased smoking and alcohol use, fatigue, distraction, elevated blood pressure, and other signs and symptoms.

\subsection{Conclusions Regarding the Medical and Health Effects of the Accident}

It will be several decades before the human health consequences of the Chornobyl accident are fully understood. Even now, only 14 years after the accident, many observations and preliminary findings indicate that previously held models and assumptions about the effects of ionizing radiation might need to be revised. The experience gained in the treatment of the acute radiation syndrome cases greatly increased our understanding and improved techniques for managing major radiation injuries. The dramatic increase in child thyroid cancer reinforces the need for prompt intervention following a major radiological accident to control population doses.

The apparent absence of a statistically significant increase of leukemia cases among the 200,000 Liquidators and the larger population in the affected areas of Ukraine, Belarus, and Russia raises important questions about existing risk models and may be indicative of the importance of dose rate and genetic repair mechanisms as major factors in carcinogenesis. Ultimately, this information also might result in revised risk estimates for some radiogenic diseases.

As our understanding of molecular biology increases, the knowledge gained through a careful study of the effects of the Chornobyl accident might also provide insights into human health risk factors beyond ionizing radiation. 


\subsection{Current Conditions at the Chornobyl Nuclear Power Plant Site}

As noted previously, Unit 3 at Chornobyl continues to operate, with a planned shutdown date of December 15,2000. There are now over 6000 workers who support the last remaining operating unit and provide support to the shutdown Units 1 and 2 and the Shelter. Following the accident, the site was subject to intense decontamination activities.

\subsection{The Shelter}

The Shelter still contains the remains of the Unit 4 reactor, most of the nuclear fuel, and radioactive material. Access to the Shelter is strictly controlled, and a $250-\mathrm{m}$-radius perimeter is maintained around the main structures. Many areas inside the Shelter have been decontaminated and are used as normal work areas for planning and preparing for long-term stabilization efforts. Other areas remain inaccessible because of very high radiation levels.

\subsection{Restoration of the Chornobyl Nuclear Power Plant Site}

Because of the extensive decontamination activities performed after the accident, on-site radiation levels are generally among the lowest found in the Exclusion Zone. The exception is the area surrounding the Shelter. Gamma radiation levels at the "Pavilion" building (the visitor facility) range from 0.05 to 0.1 millirem $(\mathrm{mrem})^{(\mathrm{a})}$ per hour. A person standing in this area for eight hours would receive a dose between 0.4 and $0.8 \mathrm{mrem}$. These levels are within the normal variability of natural background radiation and are well below radiation exposure limits for members of the general public. The average annual dose to a member of the public in the United States from all sources is approximately $360 \mathrm{mrem} / \mathrm{yr}$, or about $1 \mathrm{mrem} /$ day.

At ground level, gamma radiation levels within the restricted area surrounding the Shelter range from $0.2 \mathrm{mrem} / \mathrm{h}$ to over $25 \mathrm{mrem} / \mathrm{h}$. Access to these areas is strictly controlled.

\subsection{Airborne Radioactivity}

Airborne radioactivity measurements are made using fixed sampling stations at three locations on the plant site. Low levels of ${ }^{131} \mathrm{I},{ }^{60} \mathrm{Co},{ }^{54} \mathrm{Mn},{ }^{51} \mathrm{Cr}$, and ${ }^{59} \mathrm{Fe}$ associated with nuclear power plant operations have been detected; however, air concentrations of these radionuclides on-site are four to six times below the standard established for exposure of the general public.

(a) One millirem (mrem) is one thousandth of a rem. The rem is a unit of radiation dose. 


\subsection{Food and Water}

Because it is the workplace for approximately 6000 people, on-site food service is provided at the Chornobyl nuclear plant. All food is imported to the site from outside the Exclusion Zone and is monitored on a regular basis by the Chornobyl plant Radioecology Department.

Drinking water, which is drawn from wells $50 \mathrm{~m}$ deep, is routinely monitored. A review of monitoring results shows that the maximum expected dose to an individual worker who consumes onehalf of his or her daily intake of water at the site would be approximately $16 \mathrm{mrem} / \mathrm{yr}$. 


\subsection{Current Conditions in the Chornobyl Exclusion Zone}

\subsection{Radiation Levels}

Radiation levels within the Exclusion Zone can vary from background levels to tens of $\mathrm{mrem} / \mathrm{h}$ in the vicinity of waste storage and disposal sites. Measurements made along the driving route from Slavutych to the Chornobyl nuclear plant and from the plant to Kyiv showed no detectable readings above background.

\subsection{Airborne Radioactivity}

Levels of airborne radioactivity are monitored at several sampling stations in the Exclusion Zone. Analyses of samples taken at these stations mostly show radioactivity to be near background levels, but occasionally elevated levels occur. These levels are below the exposure limits established for members of the general public.

Because of the large accumulation of underbrush and grass on evacuated lands, brush or grass fires are not uncommon. During these fires, measured concentrations of airborne radioactivity occasionally exceed the established standards for exposure to the general public. The particles carrying the radioactivity are relatively large, so the concentration of radioactive material in the air decreases rapidly as the distance from the fire increases. Routine sampling for airborne radioactivity in the City of Slavutych has not identified any detectable levels during these fires. Persons at greater distances (e.g., Kyiv) are not expected to receive any radiation exposure as a result of these fires.

During fire conditions, persons with respiratory problems might experience discomfort or other problems unrelated to the radiation or radioactive material. At these times, it is advisable for the members of the public to avoid the smoky conditions and, if possible, to remain indoors.

\subsection{Living Quarters}

There are regulated living quarters (i.e., dormitories) within the Exclusion Zone. Most of these quarters are located in the City of Chornobyl, which is approximately $12 \mathrm{~km}$ from the nuclear plant. Anyone living in the Exclusion Zone must have specific permission to do so and is subject to limitations imposed by the State Sanitary Code.

\subsection{Food and Water}

As in the case of the Chornobyl nuclear plant, food for residents of the City of Chornobyl is imported from outside the Exclusion Zone. People should not eat food grown inside the Exclusion Zone including fruit from the trees that grow in the city. Drinking water for residents of the city is drawn from wells and has radioactivity levels comparable to potable water at the Chornobyl nuclear plant. 


\subsection{Conditions in Slavutych}

\subsection{External Radiation Levels}

Before the 1986 accident, natural background radiation levels in Slavutych were 0.009 to $0.012 \mathrm{mrem} / \mathrm{h}$ ( 78 to $105 \mathrm{mrem} / \mathrm{yr}$ ). Measurements made by the Radioecology Department of the Chornobyl nuclear plant in 1999 show that approximately $14.8 \mathrm{mrem} / \mathrm{yr}$ could be attributed to accidentrelated contamination. Background radiation levels in the wooded areas surrounding Slavutych are on the order of $0.03 \mathrm{mrem} / \mathrm{h}$. These measurements are consistent with similar measurements that have been made annually since 1991, and the measured doses are well below international (IAEA 1996b) and Ukrainian (NRBU-97) standards for radiation protection of the public.

\subsection{Airborne Radioactivity}

Air samples are routinely taken in Slavutych. Analysis of these samples shows that radiation levels from airborne radioactivity are at or near background levels. The calculated dose from the air pathway is $0.3 \mathrm{mrem} / \mathrm{yr}$. These doses are well below international (IAEA 1996b) and Ukrainian (NRBU-97) standards for radiation protection of the public.

\subsection{Food and Water}

In 1999, 87 samples of food from grocery stores and 35 samples from local garden plots were analyzed for radioactivity. The largest contribution to dose from the food pathway is through consumption of locally harvested mushrooms and game. If mushrooms and game are included as part of the average annual intake, the dose from ${ }^{137} \mathrm{Cs}$ is approximately $17 \mathrm{mrem}$; otherwise the dose is approximately $6.4 \mathrm{mrem}$. The dose contribution from ${ }^{90} \mathrm{Sr}$ in food is $4.2 \mathrm{mrem}$. Therefore, the total annual dose ranges 10.8 to $21.2 \mathrm{mrem} / \mathrm{yr}$.

The drinking water for Slavutych is drawn from wells, and the dose from ${ }^{137} \mathrm{Cs}$ present in the water is calculated to be $0.12 \mathrm{mrem} / \mathrm{yr}$. These doses are well below international (IAEA 1996b) and Ukrainian (NRBU-97) standards for radiation protection of the public.

\subsection{Total Dose to the Resident Population}

The Chornobyl nuclear plant Radioecology Department does not have the capability to perform routine analyses for transuranic radionuclides (e.g., plutonium, americium, etc.). The dose contribution from these radionuclides is estimated using environmental survey data. The plutonium contamination in the area of Slavutych is $0.0027 \mathrm{Ci} / \mathrm{km}^{2}$. Using conservative models for environmental pathways, the dose from transuranics is estimated to be $0.16 \mathrm{mrem} / \mathrm{yr}$. 
The total dose to the resident population from accident-related sources is the sum of individual doses from each of the pathways and is calculated as follows:

$$
\begin{aligned}
& D_{\text {total }}=D_{\text {external }}+D_{\text {food }}+D_{\text {airborne }}+D_{\text {water }}+D_{\text {transuranics }} \\
& D_{\text {total }}=14.8+21.2+0.3+0.12+0.16=36.6 \text { mrem }
\end{aligned}
$$

This represents approximately $10 \%$ of the average annual radiation exposure to an individual in the U.S., 360 mrem (NCRP 1987). This dose is well below international (IAEA 1996b) and Ukrainian (NRBU-97) standards for radiation protection of the public. 


\subsection{Current Conditions Elsewhere in Ukraine}

Radiological environmental monitoring in Ukraine is performed under a program jointly coordinated by the Ukraine Academy of Technical Sciences, the Ministry of Emergency Situations, and the Institute of Radiation Medicine. An annual census of radiation measurements is published. These reports indicate that the level of radioactive contamination, where detected, is decreasing on the order of 2 to $3 \%$ per year. This decreasing level of radioactivity corresponds to the rate of decay of ${ }^{137} \mathrm{Cs}$ and ${ }^{90} \mathrm{Sr}$. The only exception to this trend is activity measured in Dniper River sediments. The ${ }^{137} \mathrm{Cs}$ in river sediments is slowly being transported downstream. At the same time, however, the total inventory of ${ }^{137} \mathrm{Cs}$ in the Dniper River is decreasing over time through normal decay processes. This monitoring program provides continued assurance that the dose from accident-related contamination to the general public in Ukraine is well below regulatory limits and a fraction of natural background radiation levels. 


\subsection{Special Considerations}

\subsection{General Health Precautions}

Prior to any extended stay in Ukraine, persons should check with their health care providers for appropriate immunizations. Adequate supplies of any prescription drugs should be brought into Ukraine because of the limited availability of such products. Complete information is provided by the Centers for Disease Control and Prevention (CDC) and can be obtained from their web site at http://www.cdc.gov/ travel/

\subsection{Special Accommodations for Physical Disabilities}

Special accommodations for physical disabilities in Ukraine are limited or nonexistent. In many locations, elevators are inoperable. Persons requiring special accommodation should carefully consult with their host in advance of traveling to Ukraine. Further information is available from the CDC as noted above.

\subsection{Radiation and Pregnancy}

As noted above, radiation exposures above 10,000 mrem (10 rems) could result in birth defects. Although there are no radiological environmental conditions resulting from the Chornobyl accident that could result in such doses during the term of a pregnancy, women who are pregnant or who are considering having a child should confer with their health care provider prior to extended stays in Ukraine.

Also, because of the lack of adequate health care facilities, women who are at risk of any kind of complication during pregnancy should avoid extended stays. 


\subsection{References}

Buglova, E. E., J. E. Kenigsberg, and N. V. Sergeeva. 1996. "Cancer risk estimating in Belarussian children due to thyroid irradiation as a consequence of the Chornobyl Nuclear Accident." Health Physics $71: 45-49$.

Castronovo, F. P. 1999. “Teratogen Update: Radiation and Chernobyl." Teratology 60:100-106.

Czeizel, A. E. 1991. "Incident of legal abortions and congenital abnormalities in Hungary." Biomedical Pharmacotherapy 45:249-254.

Dewals, P. and W. Dolk. 1990. "Effects of the Chernobyl radiological contamination on human reproduction in Western Europe." Progress in Clinical Biological Research 340:339-346.

Gluzman, D. F., I. V. Abramenko, L. M. Sklyarenko, V. A. Nadgotnaya, M. P. Zavelevich, N. I. Bilous, and L. Y. Poludnenko. 1999. "Acute leukemia's in children from the City of Kiev and Kiev Region after the Chernobyl NPP catastrophe." Pediatric Hematology and Oncology 16:355-360.

Goldman, M. 1997. “The Russian Radiation Legacy.” Environmental Health Perspectives 105:S6 1385-1391.

Heidenreich, W. F., J. Kenigsberg, P. Jacob, E. Buglova, G. Goulko, H. G. Paretzke, E. P. Demidchik, and A. Golovneva. 1999. "Time trends of thyroid cancer incidence in Belarus after the Chernobyl accident." Radiation Research 151:617-625.

International Atomic Energy Agency (IAEA). April 8-12, 1996a. One Decade after Chernobyl: Summing Up the Consequences of the Accident. Vienna, Austria. Available URL: http://www.iaea.or.at/ worldatom/thisweek/preview/chernobyl/concls $17 . h$ tml

International Atomic Energy Agency (IAEA). 1996b. International Basic Safety Standards for Protection Against Ionizing Radiation and for the Safety of Radiation Sources. Safety Series No. 115, Vienna, Austria.

International Atomic Energy Agency (IAEA). 1998. Medical Aspects of the Chernobyl Accident. IAEA TECDOC-516, Vienna, Austria.

International Commission on Radiological Protection (ICRP). 1994. "Summary of the current ICRP principles for protection of the patient in nuclear medicine. A Report by Committee 3 of the International Commission on Radiological Protection." Annals of the ICRP 24(4):ix-x, Pergamon Press, New York.

Ivanov, V. K., A. F. Tsyb, E. V. Nilova, V. F. Efendiev, A. I. Gorsky, V. A. Pitkevich, Leshakov, and V. I. Shiryaev. 1997. "Cancer risks in the Kaluga Oblast of the Russian Federation 10 years after the Chernobyl accident." Radiation and Environmental Biophysics 36(3):161-167. 
Jacob, P., Y. Kenigsberg, I. Zvonova, G. Goulko, E. Buglova, W. F. Heidenreich, A. Golovneva, A. A. Bratilova, V. Drozdovitch, J. Kruk, G. T. Pochtennaja, M. Balanov, E. P. Demidchik, and H. G. Paretzke. 1999. "Childhood exposure due to the Chernobyl accident and thyroid cancer risk in contaminated areas of Belarus and Russia." British Journal of Cancer 80(0):1461-1469.

Kotz, D. 1995. "Investigating Chernobyl-Induced Thyroid Cancer: Politics versus Science." Journal of Nuclear Medicine 36:15-16, 24, 29.

Likhtarev, I. A., V. V. Chumak, and V. S. Repin. 1994. "Retrospective reconstruction of individual and collective external gamma doses of population evacuated after the Chernobyl accident." Health Physics 66:643-652.

National Council on Radiation Protection and Measurements (NCRP). 1987. Ionizing Radiation Exposure of the Population of the United States. NCRP Report No. 91, Washington, D.C.

Nuclear Energy Agency. 1996. The Chornobyl Accident Ten Years On-Radiological and Health Consequences. Paris: OECD Publications.

Oskolkov, B. Ya. 2000. Report on the Results of Radiation and Ecological Monitoring in the Vicinity of the Chernobyl NPP and the City of Slavutych - 1999. Slavutych: Special Division Chernobyl NPP.

Stsjazhko, V. A., A. B. Tsyb, N. D. Tronko, G. Souchkevitch, and K. F. Baverstock. 1995. "Child thyroid cancer since the accident at Chernobyl." British Medical Journal 310:801.

Tronko, M. D., T. I. Bogdanova, I. V. Komissarenko, O. V. Epstein, V. Oliynyk, I. A. Likhtarev, I. Kairo, S. B. Peters, and V. A. LiVolsi. 1999. "Thyroid carcinoma in children and adolescents in Ukraine after the Chernobyl nuclear accident." Cancer 86:149-156.

United Nations Scientific Committee on the Effects of Atomic Radiation (UNSCEAR). 1986. UNSCEAR Report for 1986. Annex C-Biological Effects of Pre-Natal Irradiation. United Nations Report 263-366, New York.

United Nations Scientific Committee on the Effects of Atomic Radiation (UNSCEAR). 1988a. Sources and Effects of Ionizing Radiation. UNSCEAR 1988 Report, New York.

United Nations Scientific Committee on the Effects of Atomic Radiation (UNSCEAR). 1988b. UNSCEAR Report for 1988. Annex D - Exposures from the Chernobyl Accident. United Nations Report 309-374, New York.

United Nations Scientific Committee on the Effects of Atomic Radiation (UNSCEAR). 1988c. UNSCEAR Report for 1988. Annex G-Early Effects in Man of High Doses of Radiation. United Nations Report 545-647, New York. 
Vargo, G. J., ed. 2000. The Chornobyl Accident - A Comprehensive Risk Assessment. Battelle Press, Columbus, Ohio.

Wald, N. 1992. "Acute radiation injuries and their medical management." Chapter 12 in The Biological Basis of Radiation Protection Practice, eds. K. Mossman and W. Mills. Williams and Wilkins, Baltimore, Maryland. 


\section{Distribution}

No. of

Copies

OFFSITE

$\underline{\text { PNNL - Kyiv Adjunct Office }}$

K. Deufrains (10)

DOE Forrestal

J. E. Turner, NN-30

DOE Germantown

R. L. Awan, NN-30

D. Meyers, NN-30

R. A. Reister, NN-30

Chornonbyl PMU

R. A. Robinson (3)

US Embassy, Kyiv

B. Hudspeth

S. Kornfeld (50)
No. of

Copies

ONSITE

52 Pacific Northwest National Laboratory

$\begin{array}{lr}\text { J. F. Adams } & \text { K9-64 } \\ \text { W. J. Apley } & \text { K9-01 } \\ \text { G. R. Bilyard } & \text { K3-54 } \\ \text { D. P. Couch } & \text { K7-74 } \\ \text { S. L. Dossett } & \text { P7-75 } \\ \text { A. Y. Glukhov } & \text { K7-74 } \\ \text { B. F. Gore } & \text { K8-46 } \\ \text { M. Kluse } & \text { K6-48 } \\ \text { D. K. Kreid } & \text { K7-74 } \\ \text { M. J. Lawrence } & \text { K8-02 } \\ \text { J. A. Leonowich } & \text { K3-55 } \\ \text { J. C. McDonald } & \text { K3-53 } \\ \text { R. L. Moffitt } & \text { K7-74 } \\ \text { B. A. Napier } & \text { K3-54 } \\ \text { J. K. Neal } & \text { P7-78 } \\ \text { G. R. Petersen } & \text { K7-74 } \\ \text { J. P. Schmidt } & \text { K7-74 } \\ \text { B. D. Slonecker } & \text { K7-74 } \\ \text { D. J. Strom } & \text { K3-56 } \\ \text { G. J. Vargo (25) } & \text { K3-56 } \\ \text { J. C. Wiborg } & \text { K7-74 } \\ \text { Information Release Office (7) } & \text { K1-06 }\end{array}$

Distr.1 